\title{
sciendo DETERMINATION OF REGRESSION FORMULAS FOR KEY DESIGN CHARACTERISTICS OF CONTAINER SHIPS AT PRELIMINARY DESIGN STAGE
}

DOI 10.2478/ntpe-2018-0031

\author{
Assoc. Prof. Tomasz Abramowski \\ Assoc. Prof. Tomasz Cepowski \\ Maritime University of Szczecin, Poland \\ Prof. Ing. Peter Zvolenský, CSc. \\ University of Zilina, Slovak Republic
}

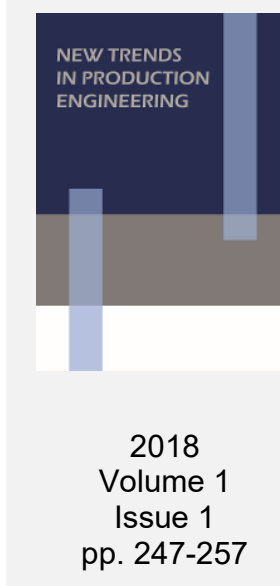

\begin{abstract}
This article presents regression equations to estimate container ship design characteristics based on the most up-to-date data and deadweight capacity, the number of containers and their combination at the preliminary design stage. These design formulas could have application for the estimation of key container ship characteristics such as: main ship dimensions, geometric parameters, main engine total power, ship velocity, final price and others. Regression equations were performed on the basis of IHS Maritime \& Trade main container ship data built from 2005-2015. All equations presented in this paper could have practical application at the preliminary design stage and increase ship design theory development.
\end{abstract}

Keywords: preliminary, ship, containership, design, main dimensions, regression

\section{INTRODUCTION}

Ship design is a multistage process. This process consists of: preliminary design, contract design and detailed design stage.

The preliminary design is an early stage of the process. Major design parameters and initial line plan, general arrangement and propulsion system are conceptualized at this stage. Rawson and (Tupper 2001, Watson 1998, Papanikolaou 2014) argue that the purpose of the parametric design is, among others to:

- select, calculate or estimate main ship dimensions, geometric parameters as well as main propulsion and powering parameters,

- arrange main spaces and compartments,

- appraise buoyancy calculations, freeboard, stability and strength on the basis of preliminary design parameters.

As noted by (Chądzyński 2001) the main objectives of the geometric design phase are to:

- design initial line plan and general arrangement,

- conduct model tests for resistance and propulsion,

- examine the calculation integrity.

The parametric design phase is greatly important for the entire design process because the design parameters that determine key ship characteristics are defined in this phase.

The modification of these parameters, at a later stage, or after the vessel is completed is far too expensive and can lead to actually making a loss. For example modifying the length of the ship after the construction of the hull is prohibitively expensive.

The main problem relating to the parametric design phase is the need to estimate different technical properties of the vessel, simply on the basis of preliminary design parameters such as a DWT deadweight capacity or a number of TUE containers.

As noted by (Papanikolaou 2014, and Chądzyński 2001) this problem can be solved by selecting a relational, statistical and a parametric design method.

Regression formulas for the determination of design parameters are usually the basis for statistical design methods. 
The authors also used a theory of artificial neural networks for this purpose. A number of papers present mathematical functions to estimate key design parameters developed through artificial neural networks theory.

The container ship is usually categorized as volume carrier in which major input design parameters are deadweight capacity and the number of containers that can be in the hold. Therefore determining container ship key design characteristics are based on these parameters.

Piko (1980) prepared regression analysis and statistical equations for many types of ships. Kalokairinos, Mavroeidis, Radou, Zachariou (2000-2005) (as cited in Papanikolaou, 2014) developed regression equations for different types of ships, including containers ship built from 2000-2005. These articles present mathematical functions for estimating container ship design characteristics based primarily on deadweight capacity.

In contrast the formulas presented by Kristensen in 2013 are based on a number of containers. These formulas were developed on the basis of ship data built to 2013. These formulas do not take into account deadweight capacity.

Ekincia et al. (2011) through the use of various computational intelligence techniques to determine general ship principal parameter, also including main engine power. Lin and Shaw (2016) developed a parametric method to accurately estimate the steel weight of a new ship at the preliminary design stage. Hou et al proposed an (2011) artificial neural network model for the principal dimension estimation of naval vessels. Though it should be noted that these methods are difficult to apply at the early parametric design stage.

\section{THE AIM OF THE RESEARCH}

All design equations should be updated frequently to increase their practical application at the preliminary design stage. But there are no regression equations to estimate container ship design characteristics based on the most recent data and a DWT deadweight capacity, a number of TUE containers and theirs combination in any literature.

Therefore, the intention of this research was to develop design formula (f) to estimate container ship design parameters $(\mathrm{Y})$, based on a DWT deadweight capacity, a number of TUE containers and others:

where:

$$
Y=f\left(D W T, T E U, X_{1}, X_{2}, . ., X_{n}\right)
$$

$\mathrm{Y}$, is estimated design parameter,

$\mathrm{X}_{1}, \mathrm{X}_{2}, . ., \mathrm{X}_{\mathrm{n}}$, are input design parameters,

$\mathrm{f}$, is a design formula to calculate selected design parameter $\mathrm{Y}$.

The following $Y$ design parameters were taken into account:

- length between perpendicular LBP from 47.5 to $383 \mathrm{~m}$,

- breadth B from 9.5 to $59 \mathrm{~m}$,

- depth $D$ from 4.5 to $30.5 \mathrm{~m}$,

- draught d from 2.18 to $16.5 \mathrm{~m}$,

- displacement Disp from 6471 to $258360 \mathrm{t}$,

- light vessel mass LV from 2032 to $61881 \mathrm{t}$,

- gross tonnage GT from 355 to $194850 \mathrm{t}$,

- main engine total power PME from 404 to $81250 \mathrm{~kW}$,

- Froude number $\mathrm{Fr}$ from 0.11 to 0.28 ,

- block coefficient CB from 0.56 to 0.83 ,

- waterplane area coefficient $\mathrm{CW}$ from 0.74 to 0.96 ,

- final price SP from 2500000 to 171000000 \$,

- velocity v from 9.3 to 29.2 knots ,

- product of the main dimension LBD from 11655 to 684590.

- ratio $L V / L B D$ from 0.03 to 0.25 ,

- ratio LBP/Disp.vol^1/3 from 4.39 to 6.61 .

vs deadweight DWT from 500 to 200000 tons and the number of containers from 20 to 20000 TEU's. 
Regression equations were performed on the basis of IHS Maritime \& Trade main container ship data built from 2005-2015.

\section{REGRESSION METHOD}

As a rule, a common regression method was applied to generating models for key design characteristics.

But the regression formulas for a number input design parameters were developed using the author's method based on a heuristic algorithm.

Standard multiplicative regression methods require simultaneous insertion to the model all independent variables and all their combinations. This may lead to an over-expanded regression model and searching for optimal equations can result in too many iterations and computations.

Therefore, standard methods are ineffective for a large number of base functions and data sets. The author developed a new algorithm to find the best result on the basis of evolution theory methods to resolve this problem. The best combinations of independent variables were randomly searched through all their possible combinations in this algorithm.

The general algorithm scheme is shown in Fig 1.

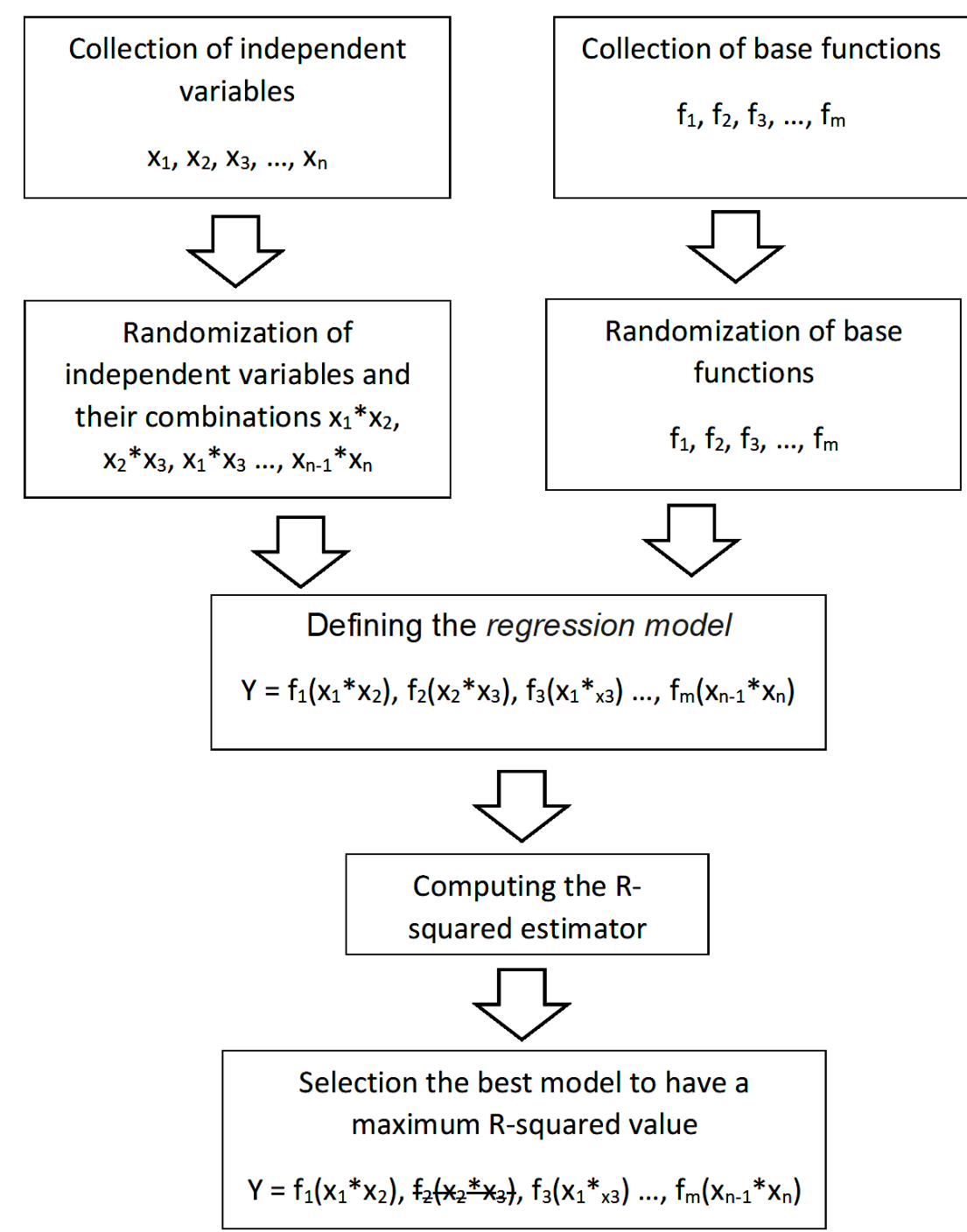

Fig. 1. The general algorithm scheme, where: $Y$, is estimated design parameter, $X_{1}, X_{2}, \ldots, X_{n}$, are input design parameters, $f$, is a design formula to calculate selected design parameter $Y, m$ is the number of formulas, $\boldsymbol{n}$ is the number of input design parameters. 
The base function collection included 360 arrays of nonlinear, exponential, power and logarithmic functions. NdCurveMaster software was applied to develop regression equations presented in this paper.

\section{THE REGRESSION FUNCTIONS FOR THE ESTIMATION OF CONTAINER SHIP DESIGN PARAMETERS}

In this section, the key container ship design parameters have each been regressed against DWT deadweight, the number of TEU containers and combinations of DWT and TEU.

The following design formulas are for the estimation of:

- length between perpendiculars

- breadth

- draught

- depth D

- gross tonnage GT

- final price SP

- block and waterplane area coefficient

- main engine total power PME

- light vessel mass LV

- displacement mass Disp

- velocity v

- L·B.D product

- L·B·d product

- ratio LV/LBD

- LBP/Disp.vol1/3

and relationship between deadweight and number of containers are presented in the next part of the article.

The study resulted in the following design formulas for the calculation of key design characteristics:

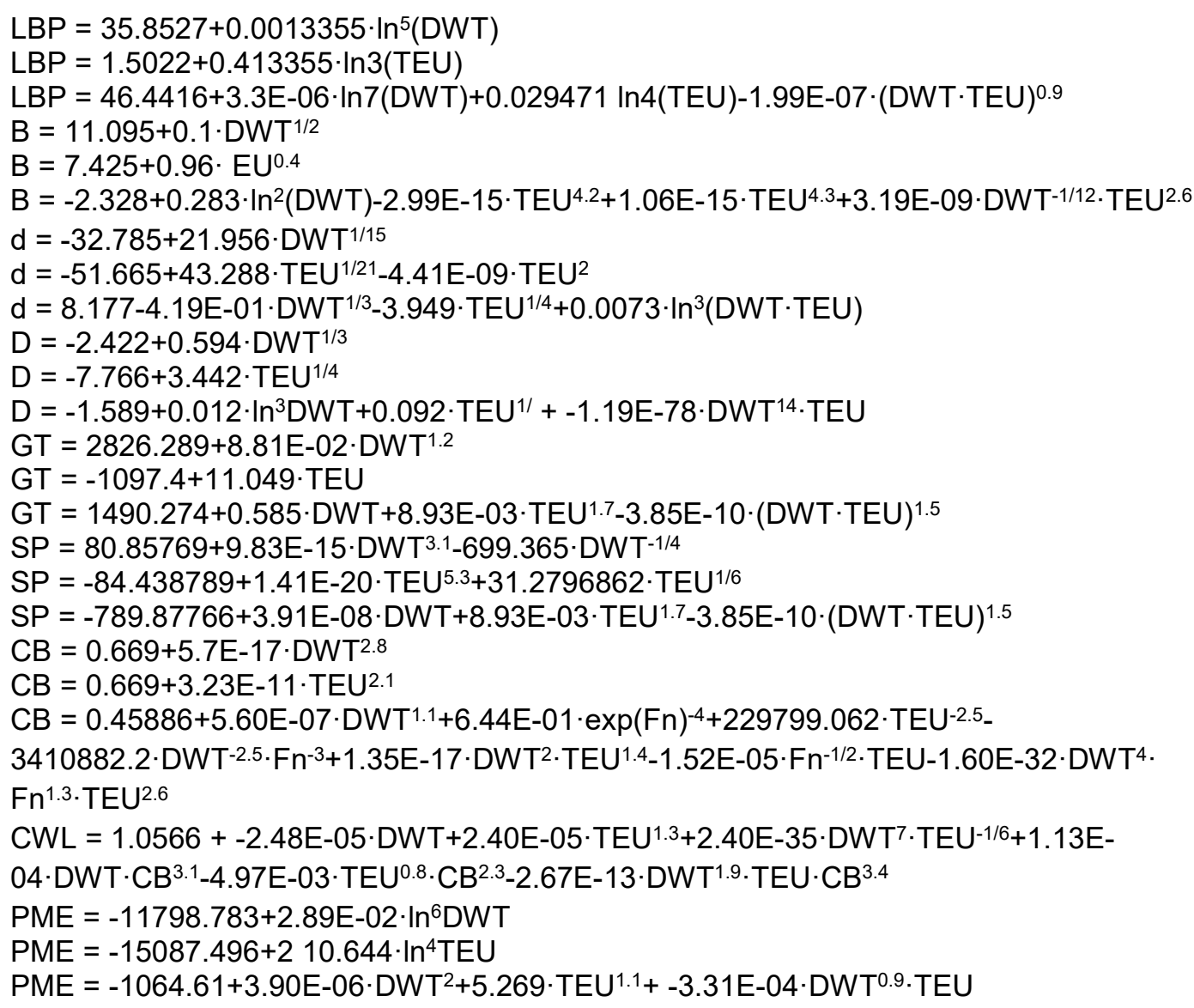


PME $=-2420.3994-4.58 E-02 \cdot \mathrm{DWT}^{1}{ }^{12+115590.89} \cdot \mathrm{Fn}^{2}+4.5857 \cdot \mathrm{TEU}^{1.1}+4.27 \mathrm{E}-$

01·DWT ${ }^{1.6} \cdot \mathrm{Fn}^{4.3}+8.88 \mathrm{E}-24 \cdot \mathrm{DWT}^{6} \cdot \mathrm{TEU}^{-0.9}-1791.82 \cdot \mathrm{Fn}^{4.2} \cdot \mathrm{TEU}^{-3.44 E-}$

$07 \cdot \mathrm{DWT}^{1.7} \cdot \mathrm{Fn}^{0.9} \cdot \mathrm{TEU}^{0.8}$

$\mathrm{LV}=228.81+0.979 \cdot \mathrm{DWT}^{0.9}$

$\mathrm{LV}=109.363+6.44 \mathrm{E}-03 \cdot \ln ^{7} \mathrm{TEU}$

$L V=2365.363+0.003 \cdot$ DWT $^{1.2}+6.60 \mathrm{E}-03 \cdot \mathrm{TEU}^{1.7}-3.70 \mathrm{E}-05 \cdot(\mathrm{DWT} \cdot \mathrm{TEU})$

Disp $=1897.963+1.2898 \cdot$ DWT

Disp $=3526.844+2.91 \mathrm{E}-03 \cdot \ln 8 \mathrm{TEU}$

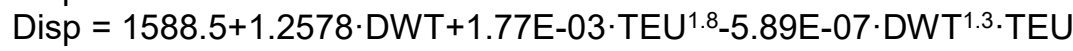

$\mathrm{v}=27.1856-985.3918 \cdot \mathrm{DWT}^{-1 / 2}$

$\mathrm{v}=27.19-276.836 \cdot \mathrm{TEU}^{-1 / 2}$

$\mathrm{v}=81.667+90.1 \cdot \mathrm{DWT}^{-1 / 8}-162.29 \cdot \mathrm{TEU}^{-1 / 12}-5.59 \mathrm{E}-08 \cdot \mathrm{DWT}^{-0.3} \cdot \mathrm{TEU}^{2.3}$

LBD $=-184.56765+1.044 \cdot \mathrm{DWT}^{1.1}$

LBD $=-20143.62+104.422 \cdot$ TEU $^{0.9}$

LBD $=-10716.896+1.2148 \cdot \mathrm{DWT}+27.9396 \cdot \mathrm{TEU}-1.30 \mathrm{E}-05 \cdot(\mathrm{DWT} \cdot \mathrm{TEU})$

$\mathrm{LBd}=-5545.44+6.194 \cdot \mathrm{DWT}^{0.9}$

$\mathrm{LBd}=-9615.46+145.23 \cdot \mathrm{TEU}^{0.8}$

$\mathrm{LBd}=907.2+1.63 \cdot \mathrm{DWT}+0.1439 \cdot \mathrm{TEU}^{1.5}-5.81 \mathrm{E}-09 \cdot \mathrm{DWT}^{1.1} \cdot \operatorname{In}^{8} \mathrm{TEU}$

LV/LBD $=1.95 \mathrm{E}-02+7.13 \mathrm{E}-01 \cdot \mathrm{TEU}^{-1 / 4}$

LV/LBD $=8.79 \mathrm{E}-02-1.55 \mathrm{E}-05 \cdot \mathrm{DWT}^{0.6}-3.5887 \cdot \mathrm{TEU}^{-1 / 2}+10.55 \cdot(\mathrm{DWT} \cdot \mathrm{TEU})^{-1 / 4}$

LBP/Disp.vol ${ }^{1 / 3}=10.3491-11.208 \cdot$ DWT $^{-1 / 12}$

LV/LBD $=5.439--2.71 \mathrm{E}-04 \cdot \mathrm{DWT}^{0.9}-1.05 \mathrm{E}-02 \cdot \mathrm{TEU}^{0.7}+4.77 \mathrm{E}-10 \cdot \operatorname{In}^{8}(\mathrm{DWT} \cdot \mathrm{TEU})$

DWT $=1317.745+2.24 \mathrm{E}-03 \cdot \ln ^{8}(\mathrm{TEU})$

TEU $=372.53+7.94 \mathrm{E}-03 \cdot \mathrm{DWT}^{1.2}$

where:

LBP - length between perpendiculars [m],

$B$ - breadth [m],

$\mathrm{d}$ - draught $[\mathrm{m}]$,

$\mathrm{D}$ - depth $[\mathrm{m}]$,

TEU - number of containers,

DWT - deadweight capacity [t],

LV - light vessel mass [t],

$\mathrm{LBd}$ - the result of $L \cdot B \cdot d\left[\mathrm{~m}^{3}\right]$,

$L B D$ - the result of $L \cdot B \cdot D\left[\mathrm{~m}^{3}\right]$,

$\mathrm{v}$ - velocity [kts.],

Disp - displacement mass [t],

$\mathrm{SP}$ - light vessel mass [t],

$\mathrm{PME}$ - main engine total power [kW],

CB - block coefficient [-],

CWL = waterplane area coefficient [-]

SP - final price [\$ million],

GT - gross tonnage [-],

Fn - Froude number [-].

The values of standard SE and the R-squared errors relating to elaborated relationships (2-50) are given in Table 1. Figures 2-5 show the relationship between design parameters and deadweight or TEU capacity calculated using formulas (2-50). 
Table 1

The values of standard SE and the R-squared errors relating to elaborated relationships (2-50)

\begin{tabular}{|c|c|c|c|c|c|}
\hline Item & $\begin{array}{c}\text { Output design } \\
\text { parameter }\end{array}$ & $\begin{array}{c}\text { Input design } \\
\text { parameter }\end{array}$ & $\begin{array}{c}\text { Equation } \\
\text { no }\end{array}$ & $\begin{array}{l}\text { Standard } \\
\text { error SE }\end{array}$ & $\begin{array}{c}\text { R- } \\
\text { Squared }\end{array}$ \\
\hline 1. & LBP & DWT & (2) & $11.53 \mathrm{~m}$ & 0.976 \\
\hline 2. & LBP & TEU & (3) & $11.27 \mathrm{~m}$ & 0.978 \\
\hline 3. & LBP & DWT, TEU & (4) & $10.32 \mathrm{~m}$ & 0.982 \\
\hline 4. & B & DWT & (5) & $1.84 \mathrm{~m}$ & 0.961 \\
\hline 5. & B & TEU & (6) & $1.82 \mathrm{~m}$ & 0.962 \\
\hline 6. & $\mathrm{~B}$ & DWT, TEU & (7) & $1.67 \mathrm{~m}$ & 0.968 \\
\hline 7. & $\mathrm{~d}$ & DWT & $(8)$ & $0.51 \mathrm{~m}$ & 0.967 \\
\hline 8. & $\mathrm{~d}$ & TEU & (9) & $0.57 \mathrm{~m}$ & 0.959 \\
\hline 9. & $\mathrm{~d}$ & DWT, TEU & $(10)$ & $0.47 \mathrm{~m}$ & 0.971 \\
\hline 10. & $\mathrm{D}$ & DWT & (11) & $1.2 \mathrm{~m}$ & 0.963 \\
\hline 11. & D & TEU & (12) & $1.21 \mathrm{~m}$ & 0.962 \\
\hline 12. & $\mathrm{D}$ & DWT, TEU & $(13)$ & $1.17 \mathrm{~m}$ & 0.965 \\
\hline 13. & GT & DWT & (14) & 3847 & 0.992 \\
\hline 14. & GT & TEU & (15) & 3555 & 0.993 \\
\hline 15. & GT & DWT, TEU & (16) & 2833 & 0.995 \\
\hline 16. & SP & DWT & (17) & \$16.82 million & 0.738 \\
\hline 17. & SP & TEU & (18) & \$16.17 million & 0.758 \\
\hline 18. & SP & DWT, TEU & (19) & \$ 16.82 million & 0.765 \\
\hline 19. & CB & DWT & (20) & 0.028 & 0.05 \\
\hline 20. & CB & TEU & (21) & 0.028 & 0.03 \\
\hline 21. & CB & DWT, TEU, Fn & (22) & 0.025 & 0.28 \\
\hline 22. & $\mathrm{CWL}$ & DWT, TEU, CB & (23) & 0.026 & 0.44 \\
\hline 23. & PME & DWT & $(24)$ & $7727 \mathrm{~kW}$ & 0.878 \\
\hline 24. & PME & TEU & (25) & $7626 \mathrm{~kW}$ & 0.882 \\
\hline 25. & PME & DWT, TEU & (26) & $6683 \mathrm{~kW}$ & 0.909 \\
\hline 26. & PME & DWT, TEU, Fn & (27) & $5086 \mathrm{~kW}$ & 0.947 \\
\hline 27. & LV & DWT & $(28)$ & $1892 \mathrm{t}$ & 0.979 \\
\hline 28. & LV & TEU & (29) & $1729 \mathrm{t}$ & 0.983 \\
\hline 29. & LV & DWT, TEU & (30) & $1573 t$ & 0.986 \\
\hline 30. & Disp & DWT & (31) & $1952 t$ & 0.999 \\
\hline 31. & Disp & TEU & (32) & $4380 \mathrm{t}$ & 0.994 \\
\hline 32. & Disp & DWT, TEU & (33) & $1581 \mathrm{t}$ & 0.999 \\
\hline 33. & $\mathrm{~V}$ & DWT & (34) & $1.45 \mathrm{kts}$. & 0.727 \\
\hline 34. & $\mathrm{~V}$ & TEU & (35) & 1.42 kts. & 0.736 \\
\hline 35. & $\mathrm{v}$ & DWT, TEU & $(36)$ & $1.28 \mathrm{kts}$. & 0.830 \\
\hline 36. & LBD & DWT & (37) & $14,816 \mathrm{~m}^{3}$ & 0.991 \\
\hline 37. & LBD & TEU & (38) & $13,145 \mathrm{~m}^{3}$ & 0.993 \\
\hline 38. & LBD & DWT, TEU & (39) & $11,851 \mathrm{~m}^{3}$ & 0.994 \\
\hline 39. & LBd & DWT & $(40)$ & $7591 \mathrm{~m}^{3}$ & 0.999 \\
\hline 40. & LBd & TEU & $(41)$ & $7484 \mathrm{~m}^{3}$ & 0.991 \\
\hline 41. & LBd & DWT, TEU & $(42)$ & $6179 \mathrm{~m}^{3}$ & 0.993 \\
\hline 42. & LV/LBD & DWT & (43) & $0.01 \mathrm{t} / \mathrm{m}^{3}$ & 0.824 \\
\hline 43. & LV/LBD & TEU & $(44)$ & $0.01 \mathrm{t} / \mathrm{m}^{3}$ & 0.812 \\
\hline 44. & LV/LBD & DWT, TEU & (45) & $0.01 \mathrm{t} / \mathrm{m}^{3}$ & 0.826 \\
\hline 45. & LBP/Disp.vol $1 / 3$ & DWT & $(46)$ & 0.25 & 0.647 \\
\hline 46. & LBP/Disp.vol $^{1 / 3}$ & TEU & $(47)$ & 0.24 & 0.669 \\
\hline 47. & LBP/Disp.vol ${ }^{1 / 3}$ & DWT, TEU & (48) & 0.22 & 0.728 \\
\hline 48. & DWT & TEU & (49) & $3823 t$ & 0.992 \\
\hline 49. & TEU & DWT & (50) & 369 & 0.991 \\
\hline
\end{tabular}



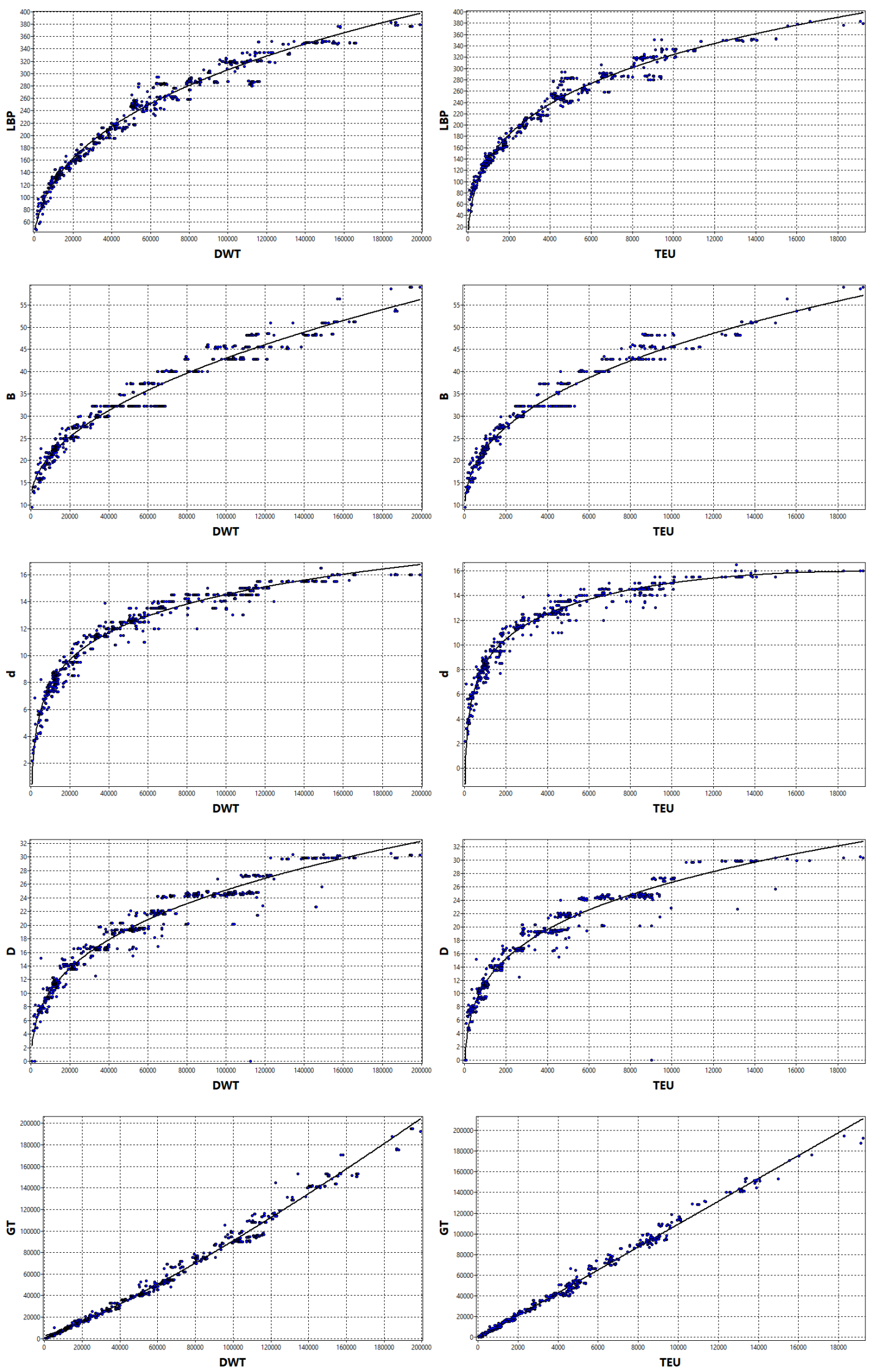

Fig. 2. Length between perpendiculars LBP, breadth B, draught d, depth and gross tonnage GT as a function of deadweight DWT or TEU capacity. 

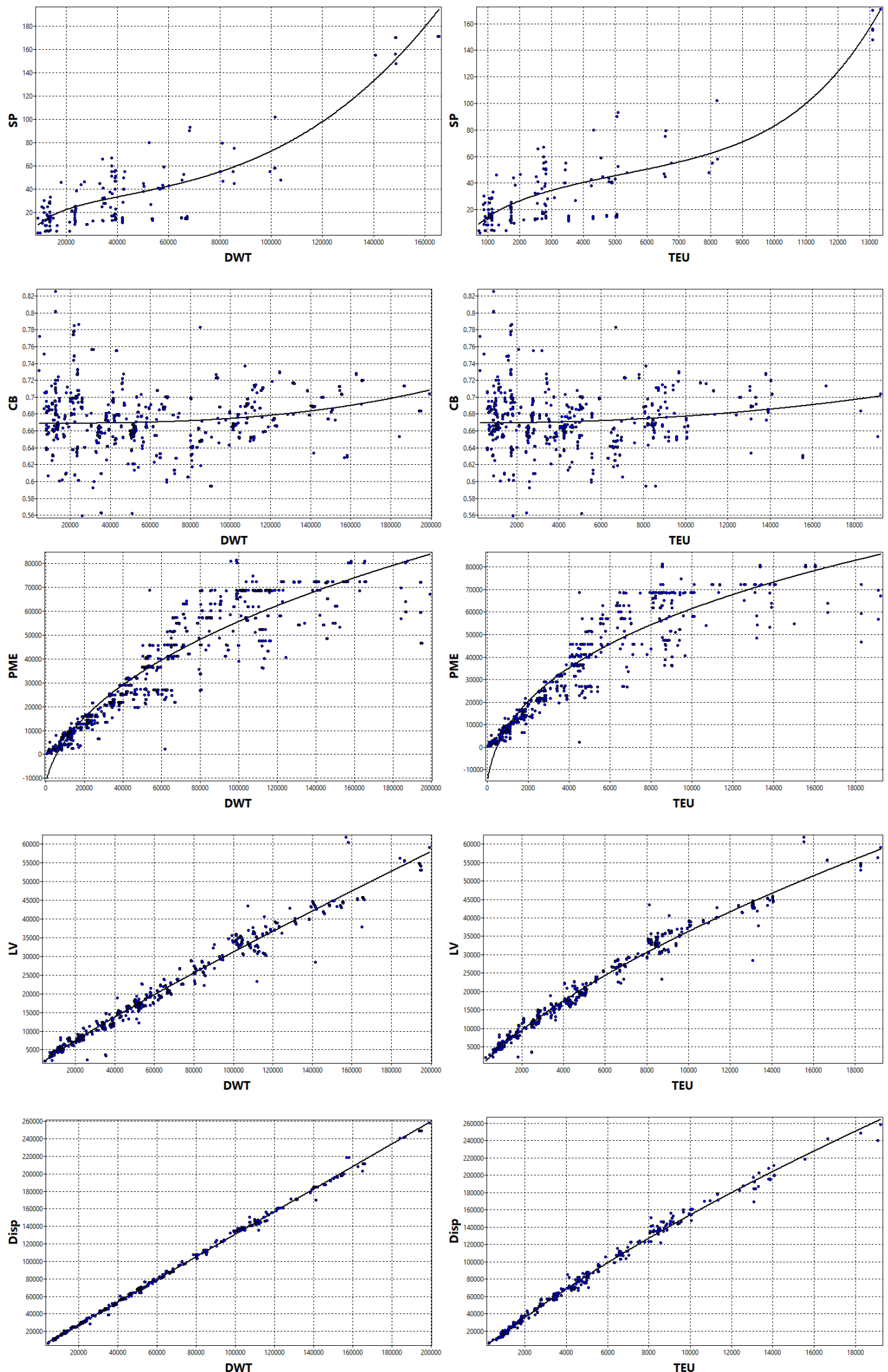

Fig. 3. Sale price SP, block coefficient $C B$, main engine power PME, light vessel mass LV and displacement mass Disp as a function of deadweight DWT or TEU capacity. 

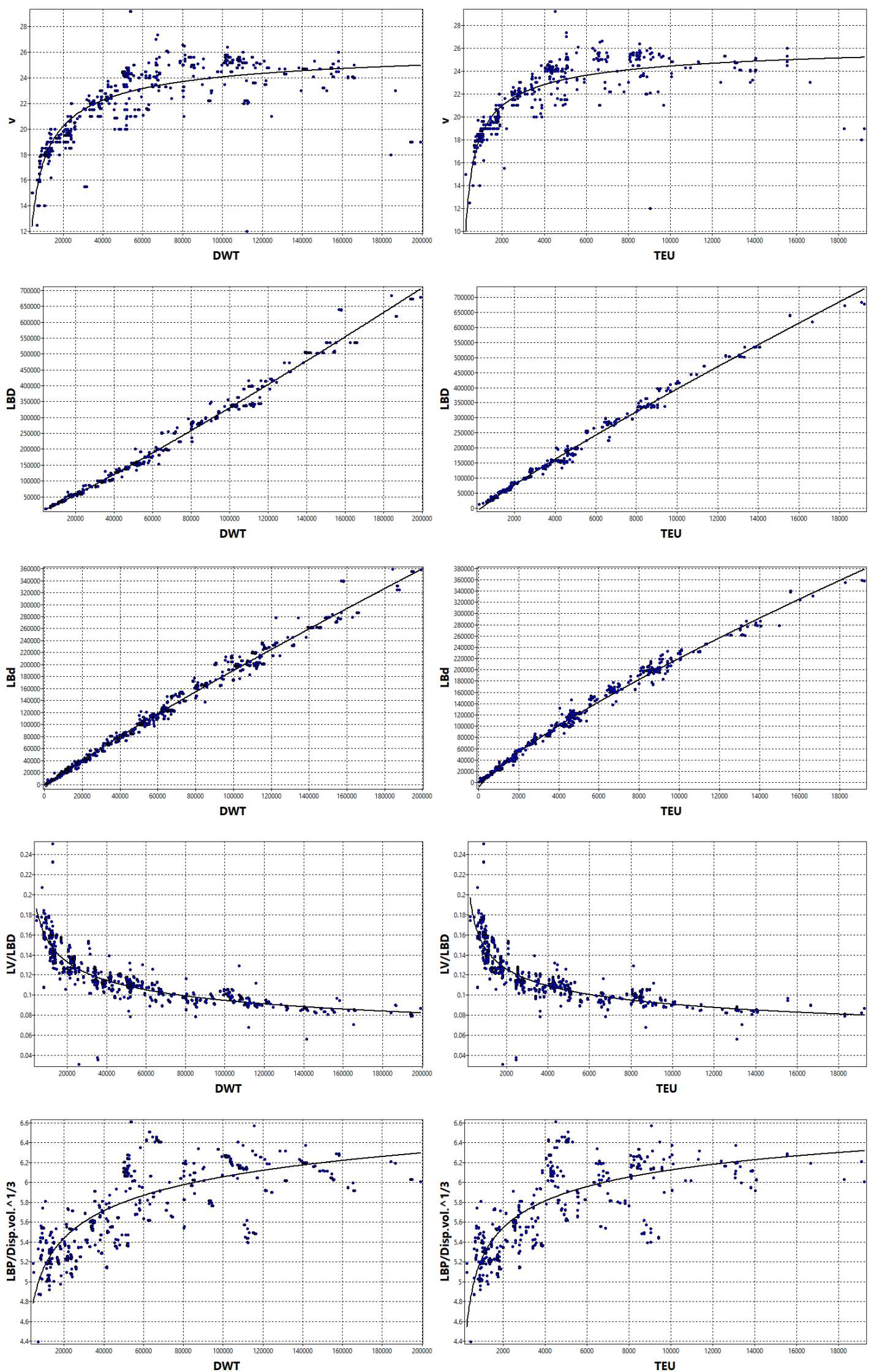

Fig. 4. Velocity v, LBD, LBd and LV/LBD and LBP/Disp.vol ${ }^{1 / 3}$ product as a function of deadweight DWT or TEU capacity. 

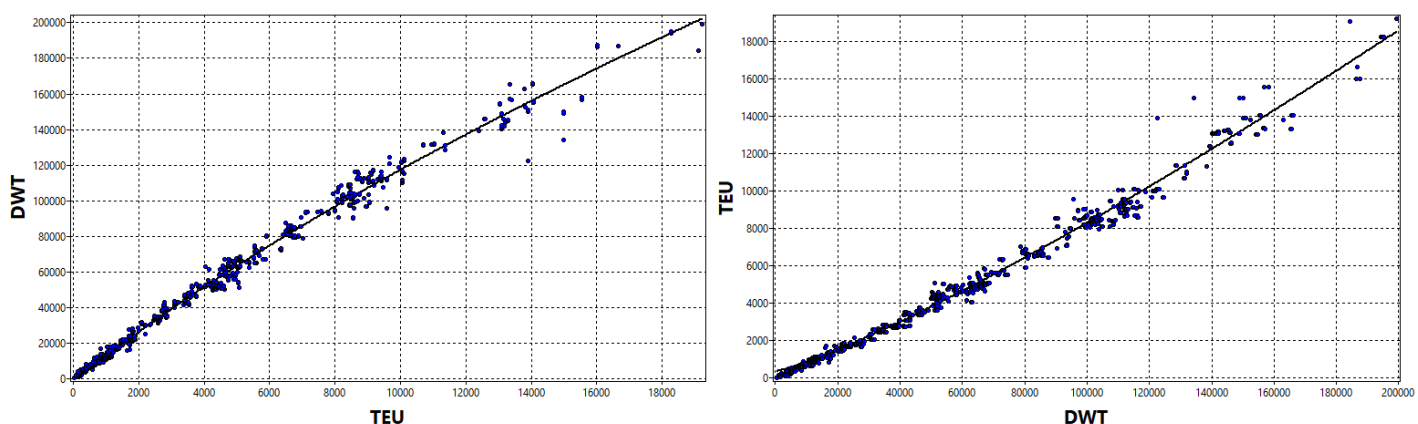

Fig. 5. Deadweight DWT against TEU capacity

\section{SUMMARY}

A new method to uncover the most suitable regression equations on the basis of evolution theory method was developed in this paper. This method uses heuristic techniques for the discovery of regression equations. The best combinations of independent variables were randomly searched through all their possible combinations in this method. The proposed method proved be effective and improved the discovery of better models.

This method has been applied to regress key container ship characteristics at the preliminary design such as:

- length between perpendiculars,

- breadth,

- draught,

- depth,

- gross tonnage,

- final price,

- block and waterplane area coefficient,

- main engine total power,

- light vessel mass,

- displacement mass,

- velocity,

and their combinations.

These design parameters have each been regressed against deadweight, the number of containers and combinations and several independent variables simultaneously, such as block coefficient or Froude number.

Generally, the accuracy of the equations presented here when using a container number variable is higher than equations only dependent on a deadweight variable.

The accuracy of all equations with many variables, is higher than equations only dependent on one deadweight or the container number variable.

The design formula accuracy for the estimation of the block and waterplane area coefficient, is low and these formulas do not have practical application. A comparison of block coefficient design formulas presented by Kristensen in 2013 indicated that the presented formulas give similar errors.

\section{REFERENCES}

Chądzyński W. (2001) Elements of contemporary design methods of floating objects (in Polish). Scientific Reports of Szczecin University of Technology, Department of Ocean Engineering and Marine System Design

Ekincia S., Celebia U.B., Bala M., Amasyalia M.F., Boyacia K. (2011) Predictions of oil/chemical tanker main design parameters using computational intelligence techniques. Applied Soft Computing 11 (2011) 2356-2366

Elvekrok D.R. (1997) Concurrent Engineering in Ship Design. Journal of Ship Production, Vol. 13, No. 4 , pp. $258-269$. 
Hou Y., Huang S, Wang W., Hu Y. (2011) Regression Analysis of Ship Principal Dimensions Based on Improved PSO-BP Algorithm, Advanced Materials Research, Vols. 308-310, pp. 1029-1032,

IHS Fairplay World Shipping Encyclopedia (2015) Maritime Sea-web Online Ship Register [Online], Available from: http://www.sea-web.com [Accessed: 12. Dec. 2015]

Lin, CK. \& Shaw, HJ. J Mar Sci Technol (2016) Preliminary parametric estimation of steel weight for new ships, 21: 227. https://doi.org/10.1007/s00773-015-0345-y

Kristensen H.O. (2012) Determination of Regression Formulas for Main Dimensions of Tankers and Bulk Carriers based on IHS Fairplay data. Project no. 2010-56, Emissionsbeslutningsstøttesystem. Work Package 2, Report no. 02. Technical University of Denmark.

Kristensen H.O. (2013) Determination of Regression Formulas for Main Dimensions of Container Ships based on IHS Fairplay data. Project no. 2010-56, Emissionsbeslutningsstøttesystem. Work Package 2, Report no. 03. Technical University of Denmark.

Papanikolaou A. (2014) Ship Design: Methodologies of Preliminary Design. Dordrecht: Springer.

Piko G. P. (1980) Regression Analysis of Ship Characteristics. Canberra: C. J. THOMPSON Commonwealth Government Printer

Rawson K.J. and Tupper E.C. (2001) Basic Ship Theory. Ship Dynamics and Design. Volume 2. Fifth edition. Butterworth-Heinemann.

SigmaLab (2017) ndCurveMaster [online copy] Available from: https://www.ndcurvemaster.com [Accessed: 4 Apr. 2017]. Szczecin, Poland.

Watson D.G.M. (1998) Practical Ship Design. Volume 1. Elsevier Science.

Date of submission of the article to the Editor: 05/2018

Date of acceptance of the article by the Editor: 07/2018 